\title{
A Place to Meet: The Art of Making the City's Street
}

\author{
Dalia Abdel Moneim Osman ${ }^{1}$
}

\begin{abstract}
Street represents the main public space for people in the outdoor environment and in some cases the only outdoor space. At the same time, the presence of people in the street provides its life. The research attempts to measure successful designed streets as places, through discussing the study of all the urban qualities, physical features and the people's reactions in the street environment. Based on a hypothesis that all of these factors may influence the way the people feel about the outdoor environment as a place for other activities. It brings into focus the importance of the street design, especially in distinctive neighborhoods as Heliopolis in Cairo. The main aim of the study is to show how the urban qualities and the physical features of the street environment have an impact on the performance of the street as a place to meet and stay. Finally, the results revealed some facts beyond the success of the design of the city's street primarily linked to the combination of some of the urban design qualities and the related physical features, together with the presence of people in the street's space.
\end{abstract}

Keywords: Street, Urban Qualities, pedestrians

\section{Introduction}

Cities have often been considered as "against" nature (Younes, 1999) or as artificial and nature less areas (Clergeau, 2008). Nowadays, the attention is drawn towards the quality of the urban environment in general, and considering in a special way the outdoor environment. As an outdoor space; the street is considered a place for experience and interaction. In general, the design of the street space is increasingly recognized as one of the key components of the development of successful neighborhoods. The good street design is reflected on the neighborhood and the quality of life. In addition, the presence of people and activities add to the quality of the street design. If people walk along a space of the street with a sense of safety, comfort and interest, hence an interaction would take place, and other people will intend to spend time in related activities along the street space.

\section{The Street Space}

Studies show that streets in the surrounded built environment have impacts on people and their activities; their design affects how and where they would walk, and consequently the overall levels of physical activities that would take place in the street's space. However, few studies have evaluated the effects of street level characteristics and the importance of aesthetics on the desirability of the street as a place to stay in or to choose to walk through (Hansen, 2014). This is taking place through the presence of 
some urban qualities. For example, people are more likely to walk or stay in the street space if they exist on high quality and aesthetically pleasing streets with features such as sidewalks, tree canopy, changing retail shops, vistas, street furniture and varied architecture (Zacharias, 2001).

\section{Valued Urban Design Qualities in the Street's Space}

There are a number of urban qualities that could be occurred in the same space of the street. However, there are many streets that are having only one quality, these are known by a singular quality that distinguishes them. A singular quality can be a special use or activity, or a characteristic spatial form and details, such as street furniture, lighting, movement or architectural style (Lynch, 1960).

Whether one or more qualities exist in the street's space, they are those design features, which make up the visual character of the street. There are eight major urban design qualities, imageability, human scale, transparency, enclosure, complexity, legibility, linkage and coherence. They appeared to be identified by users of urban spaces and that was based on visual assessment literature. However, a study (Ewing et al., 2005) stated that five urban qualities from the eight are having the criteria in order to be measured in the space. Those urban qualities include imageability, human scale, transparency, enclosure and complexity. The physical features that create these qualities can be measured. Each one of the urban design quality is linked to a physical feature in the street space, these features should be easily counted, seen and measured.

\subsection{Human scale in the street}

The first urban quality that has a strong impact on the quality of the outdoor space of the street is the human scale. Human scale could be measured by a number of items represented as street furniture, the surrounded trees, paving patterns, ornamentation of buildings and even the spacing of windows and doors that are present along its path in a defined length and in proportion to the average building height (Hanson, 2014). There are a number of elements such as street furniture, architectural details, entrances, street trees play part to human scale since they are features people are familiar with in terms of size (Ewing et al, 2005) (Orr, 1985). The existence of seating places especially those adjacent to buildings' facades help in providing the quality of human scale in the street space.

Designers have different opinions regarding the definitions of human scale according to buildings, some state that over four storeys tall are out of human scale, others set the limit as six storeys, and one (Trancik, 1986) of them suggested that lower floors should spread out and upper ones should step back, to give human scale to the street space. However, there are opinions (Arnold, 1993) related to the street trees which can moderate the scale of tall buildings. A row of trees can help to achieve human scale; a canopy of leaves and branches creates a small space within a large one. Human scale can also be defined by human speed (Kay, 1997), where many elements are designed for the accommodation of vehicles in the street space create disorientation for people, such as large signs with large lettering designed for vehicles' drivers. Hence, Human scale refers to the size, texture and articulation of any physical parts that correspond the 
proportions of people and their speed, such as the street furniture, trees, building and pavement patterns and texture.

\subsection{Imageablity and the place's image}

Imageability is defined as a quality in a physical object that evokes a strong image in the observer (Lynch, 1965). All visual features existed in the street space alone or combined together can form a sense of the image of the place and give the total figure and impression. For example, it can be identified through the existed landscape features in the street space, the signs, trees, parks or plazas. There are important elements that give meaning to the place; these elements are related to special events, values or characteristics of certain area or city. Landmarks are one example of these elements. It is the key component of imageability, not in its self only but also its singularity and location, in relationship to its context, background and the surrounded environment. Landmarks are considered as orientation points in the street space and visual termination points (Tunnard \& Pushkarev, 1963).

Imageability is affected by other qualities such as of human scale, legibility, enclosure and transparency, in some way it is the effect of these qualities (Ewing \& Handy, 2009). Urban spaces that have high rate of these qualities are likely to have high rate of imageability as well. However, the strength of the place's image evokes, whether positive or negative, but designers are focusing on the strength of positive images. Distinctive buildings are the most common kind of landmarks, such as historical, memorable or valued buildings that are characterized by their unique design, complex shapes and use (Ewing \& Handy, 2009). The surrounded environment may comprise other additional elements that may enhance those types of buildings such as the landscape elements, existence of people and the characterized architectural style.

According to the street space, it can be summarized that imageability is the quality of the street as a place that makes it distinct, recognizable and memorable. Any place would have high imageability when certain specific arranged elements capture attention and create a lasting impression (Ewing \& Handy, 2009).

\subsection{Transparency: what beyond the street}

Transparency is the ability to reach behind the street edge. If transparency exists, an interaction will take place between indoors and outdoors, buildings with wide windows invite people walking along the street space to look in and then come in to these buildings. Windows visually extend the interior out and allow people to see the interior uses which will in turn make the street level more visually complex. Openings also provide more data that enrich the experience of walking in the street and make it meaningful through visual keys of uses, access and linkage (Hanson, 2014). However transparency could be the ability to imagine what lies behind the street edge and not actually being seen. The existence of trees in the street space affects its quality of transparency, where short trees are against transparency. Tall trees create what is called partially transparent tents (Arnold, 1993) and they create a sense of enclosure at the same time.

Consequently, transparency can be defined as the degree to which people in the street space can see or perceive elements or other activities to what lies beyond the edge of the 
street (Ewing \& Handy 2009). Transparency is influenced by number or physical elements which could be the components of the street itself, for example windows, doors, fences and street trees.

\subsection{Enclosure}

The vertical elements in the space contribute to define it. The degree to which these vertical elements visually define the streets is the enclosure quality. It is known that the outdoor space is successful when it has a definite and district shape, and when its shape has the same importance as the surrounding buildings (Alexander et al., 1977). This help people to reach more with each other and with the surrounded environment as this creates a place which is defined, safe and memorable.

It is essential to obtain the right wall height of buildings to the width of the street ratio, in order to define the street space (Hansen, 2014). It was suggested a ratio of 1:2 building height-to-street width ratio (Jacobs, 1993). Also, some designers state that the total width of the street from building line to the other building line, should not exceed the building heights, so that to create a comfortable feeling result of enclosure (Alexander et al., 1977). Focal points are important at the ends of the street space if the street is not strongly defined by buildings, focal points at its ends can perceive the visual linearity of the sides of the street. They can contribute to a sense of enclosure. The street spaces can be end with monuments, fountains or any other architectural elements (Duany \& Plater, 1992).

Hence it can be concluded that enclosure is the degree to which the street space is visually defined by any vertical lines such as buildings, trees or walls. Any space where the height of vertical line is proportionally related to its width will have the enclosure quality within it.

\subsection{Complexity in the variation of street's elements}

The variation of more than one element in the outdoor space such as the architectural style, buildings shapes, ornamentation, materials and colors, create complexity. However, variations on basic patterns should be followed in order to avoid a dull sameness (Nelessen, 1994). If the street space has the quality of complexity, it will provide many interesting issues to watch or look at, for example, the building details, surfaces, materials, movement, signs, trees and people.

Variation in buildings in the street space can be implemented into the building orientation plan or even the line of buildings along the same street, this create different building frontage instead of monotonous, straight building frontage (Ewing \& Handy 2009). Even complexity can be existed through the number of different colors on buildings or the number of different building shapes along a certain length of street.

Trees are other elements that help to achieve the complexity quality in the space. When light is filtered through trees leaves and branches, it gives life to space. The contrast between light and shadow transforms asphalt and concrete into interesting scenes of sunlight and shade (Arnold, 1993). Street furniture also shares to the complexity of the street. Fountains, pedestrian-scaled street lights, benches and public art are all contribute to create special places (Jacobs, 1993). Signage is considered another important element that has a role in the complexity created in the street space, it provide interest, make the 
outdoor more inviting and help create a sense of place. However, the location, shape, color and size should be studied well in order not to make unorganized scene that could act negatively on the street space, especially when signage are lit at night, the result will be good if well studied, otherwise if it reached high complexity it will be unfriendly, chaotic and affects the street space negatively. People are important element in the street space, their presence and their activities add to the complexity quality of the place. In addition their motion even adds to the complexity. Most popular streets in different places are characterized by the presence of large number of people on sidewalks and different people activities that bring life to the street space.

Therefore, the building types, activities, street elements, modes and people if integrated together, they create diversity, which in turn adds to the complexity of the street space (Gehl, 1987). Besides the mixture of different uses such as the commercial or residential ones in the same space would create diversity as well, creating pedestrian traffic during the whole day which in turn resulting in the safety or the interesting character of a place. It can be summarized that complexity is created in the street space when variation occurred visually in the physical elements, such as the architectural style and ornamentation, the number and types of buildings, street furniture, signage and the existence of people and their activities (Jacobs, 1961).

\section{Physical Features and the Street's Visual Character}

The physical features in the space results in the visual character of the street, they influence the quality of the street space and the walking or staying chance in the street. This takes place both directly and indirectly through the perception and sensitivities of people. Perception is the way of gaining awareness or understanding of senses' related information, people perceive is a result of interplays between past experience, their culture and the interpretation of the perceived (Ewing \& Handy, 2009). The urban design qualities are defined and illustrated by physical features which in turns create these qualities. There are a number of features for each urban design quality that contribute significantly to each one. All the street furniture, physical elements and streetscape are related to human scale, together with the building heights. The presence of parks, courts and plazas influences the imageability quality, in addition to valued or historical buildings. The facades of the ground floors and windows of their spaces strengths the transparency quality.

The enclosure quality is affected by the proportion of the street wall represented by buildings, the skyline, trees and even the arches and shelters. The variation of buildings, their colors and styles affect the complexity quality together with the presence of people along the street space.

\section{People Interactions in the Street Space}

The desire of attract people to any outdoor space has been an inherent goal in urban design. This was started by encouraging people to walk and designing a more walkable environment. Studies were concentrated on the sensorial qualities; others emphasized the role of social qualities of the environment besides the sensorial qualities. 
Urban designers are also interested in the outdoor environment as a social setting - a place that provides sensory stimulation but also supports the desired behaviors of its users. There are three main Factors that should exist in order to encourage people to present in the street space. The urban design qualities and the physical features strengthens the space, however there should exist safety, comfort and interest factors in the street space for people to exist. This helps interactions to take place and consequently the street becomes a place to meet.

\subsection{Safety}

The term safety refers to all the elements and the ways needed to minimize the possibility of occurrence of the risk arising from a society crime or a traffic accident while walking or staying in the street (Osman, 2016). Buffer should exist to avoid a direct conflict between transportation and pedestrian space, and there are other measures and physical features to perceive safety such as speed limits, traffic calming measures or using trees or plantings to reduce or slow down traffic. Facilities and plans should be installed to prevent crimes, studies showed that the sense of perceived safety from crime on the street is affected by environmental characteristics such as the physical condition and maintenance of the environment, the configuration of streets, types of land uses, the presence or absence of, and the kind of people (Mehta, 2008). Streets are safer where there is a presence of stores and other non-residential properties on the street (Perkins et $a l, 1993)$. In addition the presence of people increases the perception of safety in the street space (Newman, 1972).

\subsection{Comfort; Physical and environmental}

There are physical and environmental factors that affect the street environment to provide the ability for a person to walk or stay in the place. Comfort refers to all what provides convenience to people especially pedestrians; they will feel refreshing during walking by a good composition of the surrounded environment of the space. It is important to provide convenience through the presence of various facilities required to encourage the flow of pedestrian and ease walking without discomfort. Studies showed that comfortable microclimate conditions, including temperature, sunlight and shade, and wind are essential to support outdoor activities. It is important to offer protection from sun, wind and rain (Mehta, 2008). In addition, the street should offer physical comfort conditions, by providing elements in the street design such as generous sidewalk width, trees, shade and shelter, aesthetic elements and traffic calming measures.

\subsection{Level of Interest}

This refers to every pleasure that perceived from the street environment, from the lights, sounds, smells, colors, shapes, textures or patterns. It is argued that to achieve interest in the street space, a moderate level of complexity should take place. Urban designers note that the interest gained in the street are perceived from, but not limited to, the architectural style and ornamentation, shop windows and the goods canopies, signage (Rapoport, 1990). Also the street furniture, landscape elements, people and in turn related activities, including even movements and sounds (Zacharias, 2001). 


\section{Introducing Heliopolis History}

Heliopolis is a neighborhood in Contemporary Cairo created to the northern east of the site of the old city. It was built in the year 1908 by the Belgium Industrialist "Baron Empain". He planned to build a new city in the desert, he constructed the city's construction company first in the year 1906 (American University Press, 2006) which is called "Heliopolis Oasis Company".

The headquarters of the company still occupy the same building up till now on "Boulevard Abbas", it was the first building to be constructed in the new city, see fig. 1.
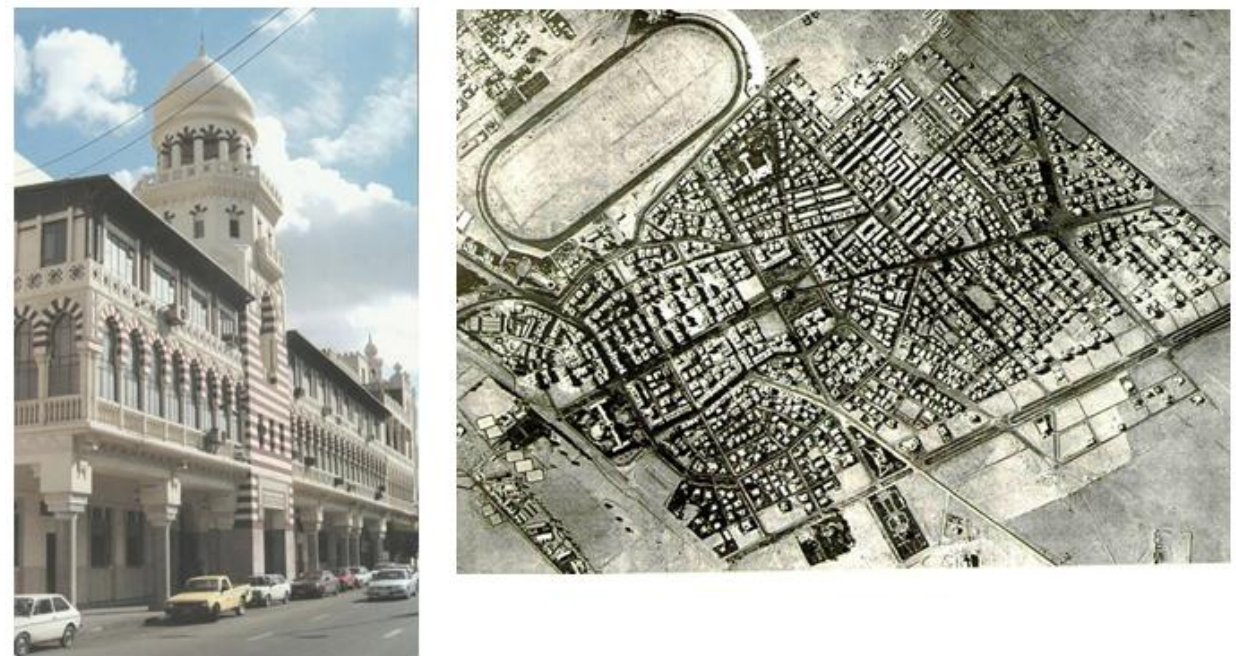

Fig. 1 left, The Heliopolis Company's Headquarters. Right, The Mass plan of Heliopolis in the year 1930.

Although much has changed in Heliopolis since first constructed, yet many of the constructed buildings are still exist, the same with the urban form of the city. According to its original plan, Heliopolis was to cover 2.500 hectares (Ilbert, 1981) including wide open green spaces and dwellings of all types, ranging from villas to very small workers dwellings. There was variety of buildings that attracted all the community's classes. Luxury buildings were constructed yet a special area of the new city was designated to house workers and servants (Osman, 2016). Their houses were economical but they were designed to provide good conditions for living.

\section{Heliopolis: The Art of Making a City}

Heliopolis is considered one of the most distinguished neighborhoods in the city of Cairo; it became today one of the poles of development in Greater Cairo. It was not the result of a rapidly developing private enterprise or just a large residential project; it was a creation of a real city with its own multiple services. Residential buildings were arranged around huge common courtyards, and were entered from small pedestrian streets extending between green areas, therefore offering greenery and privacy even 
though these buildings were located on a main street. This was a kind of Urban Design that was discussed in the progressive European architectural Journals of that time (Osman, 2016).

Although there were a creative and new adaptation of urban design concepts that had been present in European urban planning at that time, this was clear in the buildings that have been built around courtyards, opened onto a common space planted with greenery and designed landscape. This resembled "Place des Vosges" and "Place Dauphine" in Paris, as well as the British housing created around greenery squares (Ilibert, 1981).

\subsection{Challenges and Town Planning Success}

The founder "Baron Empain" had three challenging features. In the first place, it was built without any assistance from the state; secondly, the new town was to be set up from scratch and built in the desert; and at last, it was the expression of one's individual's personal dreams "Baron Empain" and not the outcome of a town-planning project, but the manifestation of a concept which was very much in vogue at the time, that is "The Garden City". These three challenging issues explain the skepticism created towards the project, and the fascination which its successful implementation impacts the community today.

Heliopolis was a work of a Belgian financier, built by architects of different nationalities (Belgian, French and British architects), its architecture is could not but named Colonial exhibitions, however, it had been successfully onto the urban structure of Cairo with a unique design and urban form. From the perspective of town planners, Heliopolis is a city that had come to life in the desert.

\subsection{Heliopolis's Model and Travel Pattern}

Regarding the model, Heliopolis is more of a "garden city" than a "parallel town" in form and structure (llibert, 1981). In the first place it was designed as an isolated unit, its situation in the desert being intended to reduce the risks of being totally linked with Cairo. Although it is planned in zoning; a quarter with villas and palaces, a quarter with apartments and a quarter with workers dwellings and factories, it did not result in any barriers such as physical or psychological ones, which was existing in other parts in the City of Cairo at that time, see fig. 2. The principles used in planning Heliopolis were those just being introduced in Paris. This includes height of the buildings and the percentage of ground to be occupied which were strictly regulated.

Regarding the travel pattern, Heliopolis's streets form a simple and symmetrical framework. The streets are keeping their form and pattern till present. They are representing $35 \%$ of the built environment; and classified into three main types, main streets $(50-60 \mathrm{~m})$, secondary street $(28-50 \mathrm{~m})$ and local streets $(12-28 \mathrm{~m})$ (Masr Al Gadidah Company, 1965). One of the fascinating ideas in planning streets is their width, where they were calculated on the basis of regulations which took into account _even in 1906 the motorized or vehicle movement. The Metro was being built from the beginning of the first buildings; this made Heliopolis within minutes of the downtown of the City of Cairo. This was considered at that time ultra-modern means of Transport, see fig. 3. 


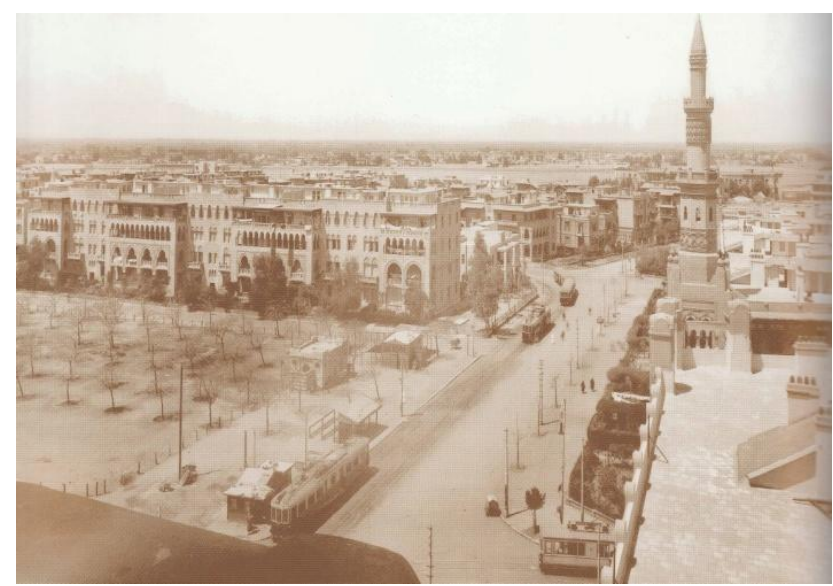

Fig.2 The northern corner of the Basilica Square in the 1920s. This used to be dividing line between the luxurious section of Heliopolis to the left, and modest housing to the right.

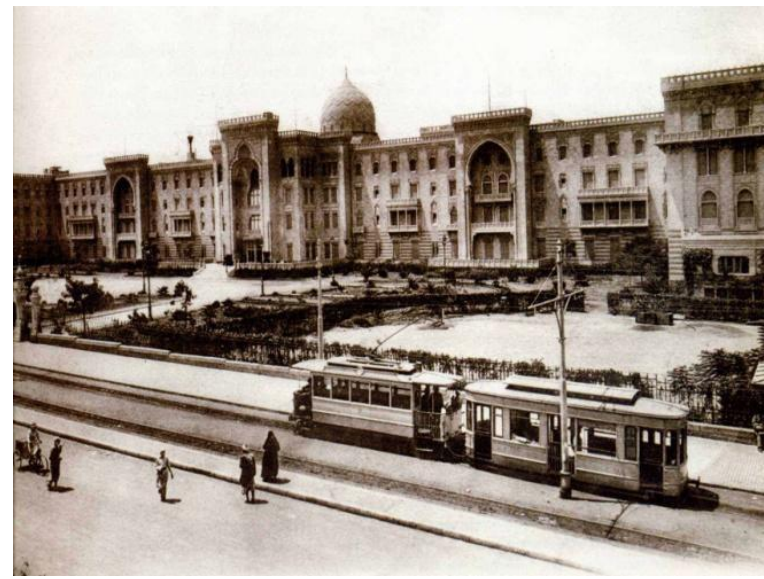

Fig.3 The Metro in front of Heliopolis Palace Hotel

\subsection{The street: A place to meet}

Heliopolis comprises major urban qualities in the outdoor space. The street design has qualities together with related physical features that influences the people's reactions towards the street space and impacts the performance of the street as a place to meet and stay. The characterized historic buildings strengths the imageability quality of the street space, the distinctive architecture makes the place memorable.

Landmarks has a share in this quality where Heliopolis has the "Basilica", the "Heliopolis Palace Hotel", the "Baron's Palace", the "main mosque and other monumental buildings". They are creating focal points connected by wide streets and avenues to create grand villas. There all represent a major guide as well to people along the streets. Also the presence of courtyards, plazas and the main park "The Merry Land", strengths this quality. The buildings have been built around courtyards, opened onto a common space planted with greenery, see fig. 4 . 

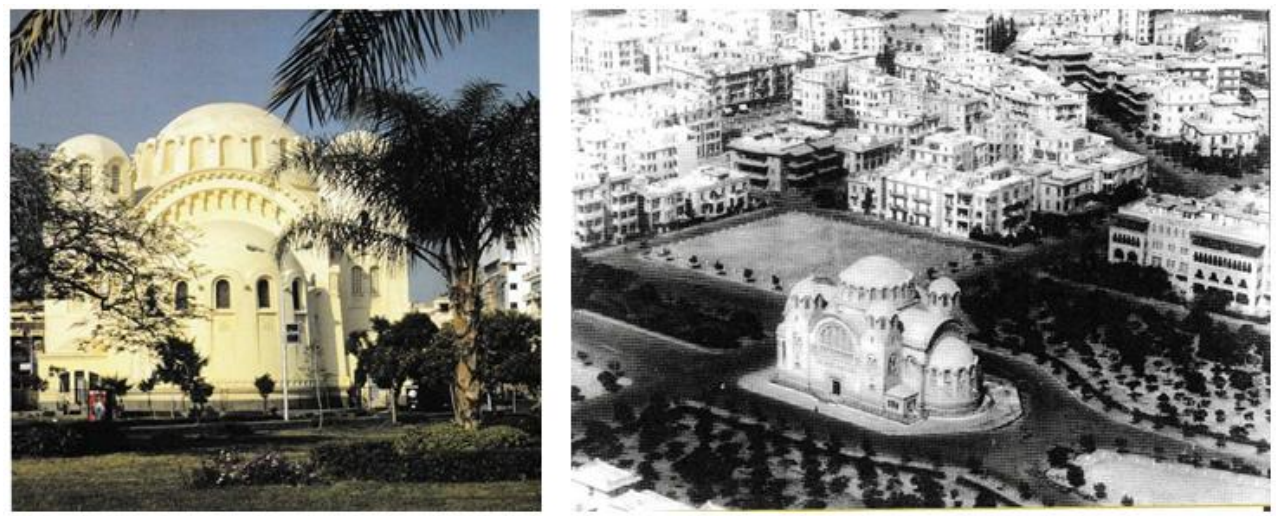

Fig.4 The Notre Dame Basilica built in the year 1911, opposite, an aerial view of the Basilica in the 1940s.

The human scale quality appeared through the significant physical features of the greenery along the street space, especially on sidewalks between the path for pedestrians and the driveway for vehicles, see fig. 5. All street furniture and other street items strengths this quality and they are not interfering with pedestrians' movement, such as shaded benches and lighting columns. The flower boxes and small planters have a role towards the human scale in the street space, where they are located along the path.

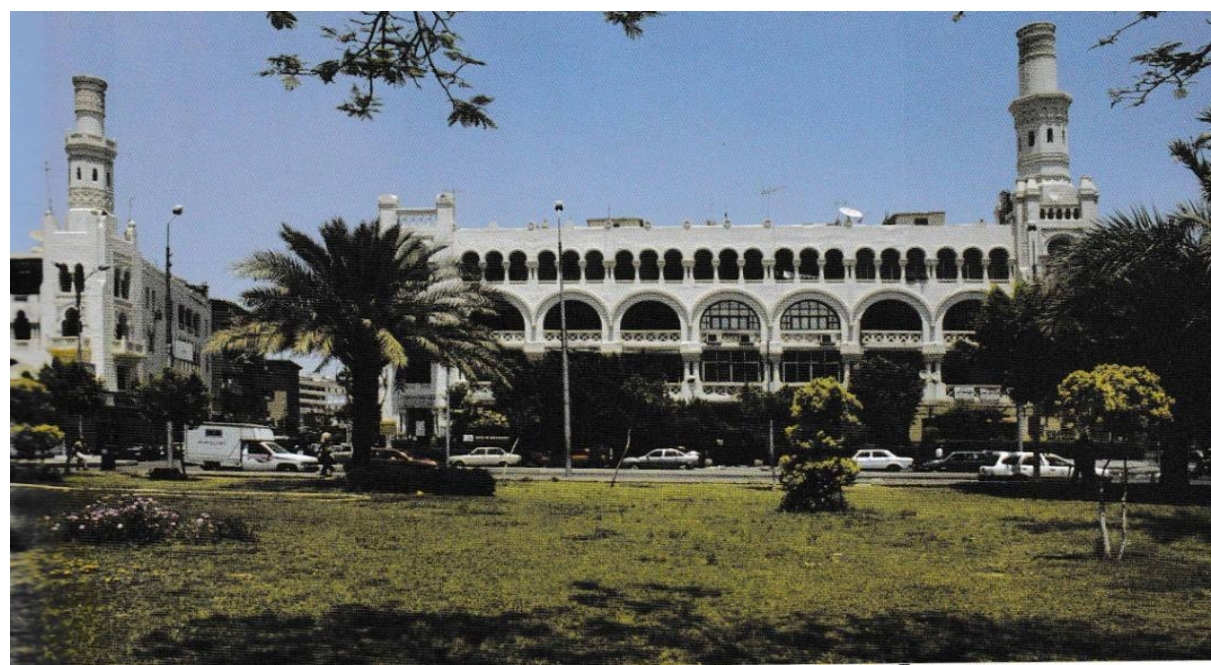

Fig. 5 The northern side of the Basilica square, where there is a significant greenery along the street space.

The distinctive street wall that representing the buildings' façade adds the complexity quality to the outdoor space. The front facades of all buildings on the main streets of "Kurba" are shaded; they are arched as well with columns. Although these columns were structural, not just for decorative, they brought complexity to the street space which in turn reflected on people's reaction towards the place, see fig. 6. 
Fig. 6 The Distinctive wall of the street
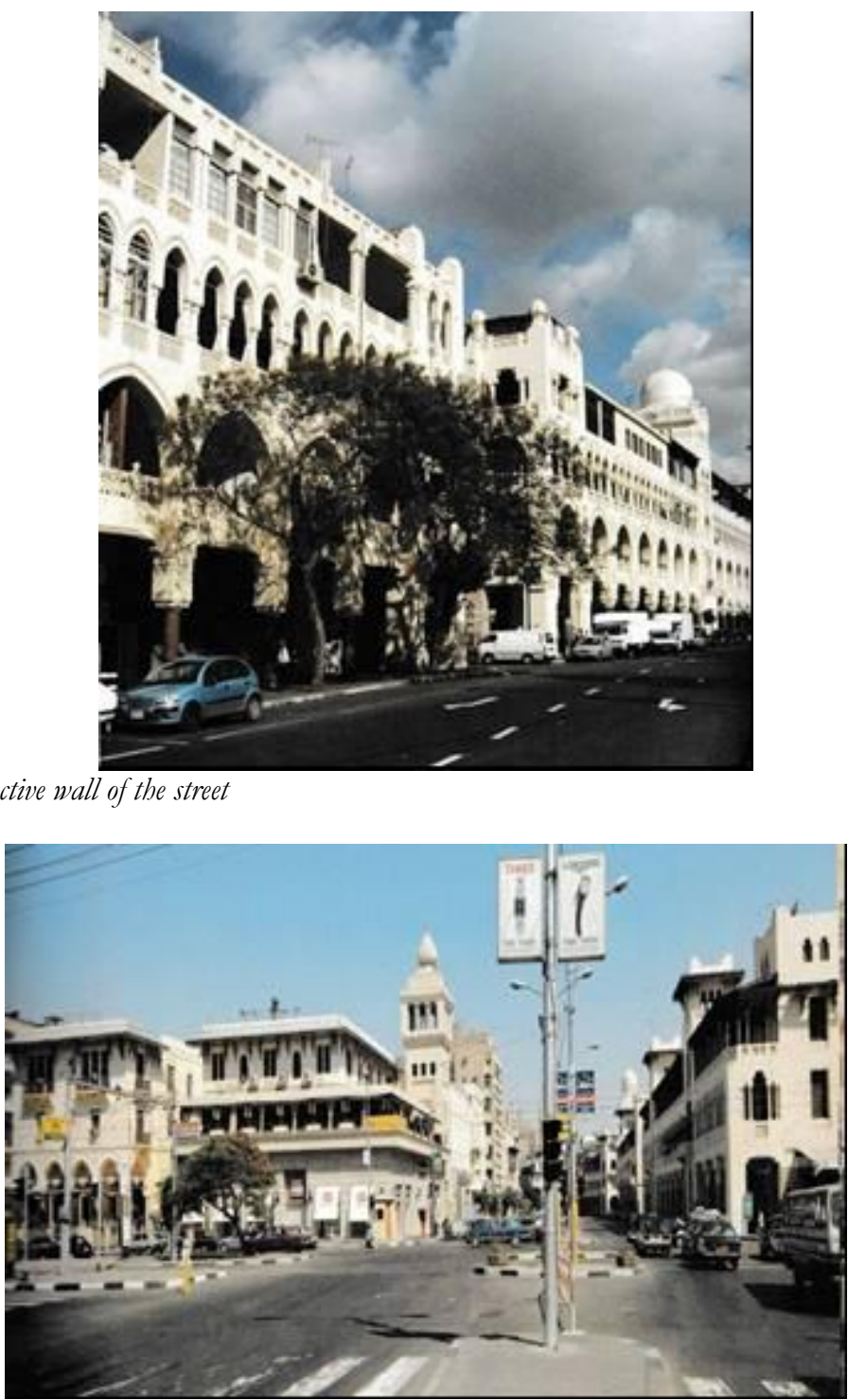

Fig. 7 Sshops, cafes and restaurants along main streets.

The presence of shops, cafes and restaurants along most main streets represent attractive points to most people and assures the transparency quality by their facades and proportion of active uses to the building. An interaction is taking place between the street space and the indoor space, leading to a perception of human activity beyond the street. The cafes and restaurants or the colonnades, arcades, street furniture, tables and seats all encourage outdoor dining as well which make a street a place to meet and stay, see fig. 7 .

The use of arcades, colonnades, balconies, awnings and shelters in the characterized architecture of Heliopolis. The front facades of all buildings on some of the major streets 
in the "Kurba" area are shaded and arched with columns, providing pedestrians' shaded pathway, along the sidewalk. This all create the enclosure urban quality of the street space. Together with the buildings heights and the street width. Street trees existed in any open space in the area that play an important role in assuring the enclosure as well, their spacing and type create long sight lines. The proportion of street wall of both sides is designed in a balanced degree. No high rise buildings are existed like those in the area of the downtown of the city of Cairo.

\section{Conclusion}

It is concluded that the urban design major qualities, physical features and the people's reactions in the street space, are all contribute to the success of the street's space as a place to meet. They strength the fact that street is not only a link, but it is also a place.

Heliopolis or the new city at that time owes its survival to its travel pattern and communication routes. The art of making the city was started by thinking and designing of both the street and the modes. Walking along Heliopolis, enchanted by the aesthetic and the feeling of history, the streets give a space for a range of interests and public lives or activities that are difficult to unfold or ignore. Valued qualities had existed in the street's space of Heliopolis. Human scale was clear in relation to many physical parts that correspond the proportions of people, the strong place's image revealed the imageability of the street's space with the characterized architectural style, transparency quality was strengthened by the characterized facades of the ground floors. Enclosure is clear in the defined vertical lines of the street; finally, the diversity of building types, street elements, modes and people added to the complexity of the street space in Heliopolis. Today, Heliopolis is a unique case in the center of thoughts about urban transformation. This undertaking succeeded not only because it was able to attract potential inhabitants, but because so many of the inhabitants of Cairo have loved Heliopolis and today take pride in considering themselves Heliopolitans.

The purpose of the street space in the neighborhood is to provide an arena in which social, economic and civil interests can meet and interact. Rather than a space where walking takes place of people, the street space is a place or a room for passive interactions. However, it is important that to realize that no definite or physical design can balance completing interests over long term of time. In order to provide lasting change, designers should be aware of the systemic forces, impacting the urban realm. The forces and changes over time in uses, community, mobility and people activities should be updated in order to fulfill the completeness of the success of the design of the street space over time.

\section{Recommendation}

Streets should provide a space with a sense of comfort, safety and interest to people in order to encourage its role as a place. In order to assure this, it is recommended that the street space should comprise the major urban qualities, their related physical features and consequently the people's interactions in the street 
environment. Researches can measure all the required qualities and variables to concern when dealing with public outdoor space particularly the street space. Planners and designers can assess these qualities in an evaluation of any outdoor space in order to conclude the real problems existed, put different strategies to improve the space and give the attention to physical features required to be associated with urban qualities in the street space.

\section{References}

Alexander, C. , Ishikawa, S. \& Silverstein, M. (1977). A Pattern Language.Towns, Building, Construction. New York : Oxford University Press.

Arnold, H. (1993). Trees in Urban Design. New York : Van Nostrand Reinhold. Clergeau, P. (2008). Préserver La nature dans La ville. (Preserving Nature in the City).

Duany, A. \& Plater-Zyberk, E. (1992). The second coming of the America Small town. Wilson Quarterly, 16, pp. 19-48.

Ewing, R., O. Clemente, S., Handy, R. Brownson, and E. Winston. (2005). Identifying and Measuring Urban Design Qualities Related to walkability. Final Report. http://www.activelivingresearch.org/node/10636.

Ewing, R. , Handy, S. (2009). Measuring the Unmeasurable : Urban Design Qualities related to Walkability. Journal of Urban Design, 14 : 1, 65-84.

Gehl, J. (1987). Life Between Buildings_Using Public Space. New York : Van Nostrand Reinhold.

Hansen, G. (2014). Design for Healthy Communities : The Potential of Form-based codes to create Walkable Urban Streets.

Journal of Urban Design, Vol. 19, No. 2, 151-170. Routledge, Taylor \& Francis Group Ltd.

Ilbert, R. (1981). Heliopolis : Colonial Enterprise and Town Planning Success? (Heliopolis : Le Caire 19051922, Genése d'un ville). Centre régional de Publications de Marseile.

Jacobs, A. (1993). Great Streets. Cambridge, MA : MIT Press.

Jacobs, J. (1961). The death and life of Great American Cities. New York : Random House.

Kay, J. H. (1997). Asphalt Nation : How the Automobile took over America, and How we can take It Back. Berkeley, CA : University of California Press.

Lynch, K. (1960). The image of The City. Cambridge, MA : Massachusetts Institute of Technology Press. Masr Al Gadidah Company (1965). Heliopolis Suburb, Past and Future.

Mehta, V. (2008). Walkable Streets : Pedestrian behavior, perception and attitudes. Journal of Urbanism : International Research on Placemaking and Urban Sustainability.

Nelessen, T. (1994). Visions for a New American Dream. Washington DC : American Planning Association. Newman, O. (1972). Defensible Space : crime prevention through urban design. New York, NY : Macmillan. Orr, F. (1985). Scale in Architecture. New York : Van Nostrand Reinhold.

Osman , D. (2016). A Tale of A Sidewalk; the Conflict of Its Presence and Usage in the Streets of Cairo. European Journal of Sustainable Development, 5, 2, 1-12.

Perkins, D. et als. (1993). The Physical environment of street crime : defensible space, territoriality and in civilities. Journal of Environmental Psychology, 13, 29-49.

Rapoport, A. (1990). History and precedent in environmental design. New York, NY : Plenum.

Trancik, R. (1986). Finding Lost Space- Theories of Urban Design. New York : Van Nostrand Reinhold.

Tunnard, C. \& PushKarev, B. (1963). Man-made America- Chaos or control ?. New Haven, CT : Yale University Press.

The American University in Cairo (2006). Heliopolis; Rebirth of the City of the Sun. The American University Press. New York. Younés, C. (1999). La ville contre-nature (The City against Nature). Editions La Découverte, Paris.

Zacharias, J. (2001a). Path Choice and Visual Stimuli : signs of human activity and architecture. Journal of Environmental Psychology, 21, 341-352.

Zacharias, J.(2001). Pedestrian Behavior and Perception in Urban Walking Environments. Journal of Planning Literature, 16(1):3-18. 